\title{
PENGARUH PENGGUNAAN TANAH MERAH SEBAGAI FILLER PADA CAMPURAN ASPAL AC-BC TERHADAP NILAI MARSHALL
}

\section{EFFECT OF RED SOIL AS A FILLER IN ASPHALT AC-BC MIXTURE ON MARSHALL VALUES}

\author{
Evie Dwi Labora Bancin, Kamaluddin Lubis, Nuril Mahda \\ Program Studi Teknik Sipil, Fakultas Teknik \\ Universitas Medan Area, Indonesia
}

*Corresponding author: evielabora@gmail.com

\section{Abstrak}

Filler merupakan material pengisi dalam lapisan aspal. Pada penelitian ini Tanah merah digunakan sebagai Filler yang lolos saringan No.200 pengganti semen yang umum digunakan pada campuran lapisan aspal. Kekuatan campuran ini adalah pada agregat- agregatnya yang saling mengisi. Dalam penelitian ini jumlah Filler yang digunakan dua variasi yaitu $2 \%$ dan $4 \%$ untuk setiap kadar aspal yang digunakan yaitu 4,5\%; 5\%; 5,5\%; 6\%; 6,5\%. Tujuan dari penelitian ini adalah untuk mengetahui pengaruh penggunaan Tanah Merah dalam campuran laston AC-BC terhadap sifat karakteristik parameter Marshall. Penelitian ini menggunakan metode Marshall berdasarkan SNI dan Spesifikasi Kementrian Umum Direktorat Jendral Bina Marga. Hasil pengujian Marshall menunujukkan nilai stabilitas rata- rata penggunaan Filler Tanah Merah dengan variasi 2\% sebesar $1325 \mathrm{~kg}$ dan kelelehan sebesar 3,40mm sedangkan pada penggunaan Filler Tanah Merah dengan variasi 4\% memiliki nilai stabilitas rata- rata sebesar $1265 \mathrm{~kg}$ dan kelelehan 3,55mm. setelah dilakukan pengujian Marshall didapatkan hasil yang menunjukkan bahwa penggunaan Tanah Merah pada campuran aspal dapat dijadikan sebagai sebagai bahan pengisi rongga (filler) campuran lapisan aspal AC- BC.

Kata Kunci: Filler, Tanah Merah, Aspal, Marshall

\section{ABSTRACT}

Filler is a filling material in the asphalt layer. In this study, Tanah Merah was used as a filler that passed the No.200 sieve replacement for cement which is commonly used in asphalt layer mixtures. The strength of this mixture is in its complementary aggregates. In this study the number of fillers used were two variations, namely 2\% and 4\% for each asphalt level used, which was 4.5\%; 5\%; 5.5\%; 6\%; 6.5\%. The purpose of this study was to determine the effect of the use of Red Soil in laston AC-BC mixes on the characteristic characteristics of Marshall parameters. This research applied Marshall method based on SNI and The Spesification General Ministry of Directorat Bina Marga. Marshall test results show the average stability value of the use of the Red Soil Filler with a variation of $2 \%$ by $1325 \mathrm{~kg}$ and a melt of $3.40 \mathrm{~mm}$ while the use of the Red Soil Filler with a variation of $4 \%$ has an average stability value of $1265 \mathrm{~kg}$ and a melt of $3.55 \mathrm{~mm}$. After the Marshall test, the results show that the use of Tanah Merah in the asphalt mixture can be used as a filler material for $A C$-BC asphalt layer mixture.

Keywords: Filler, Tanah Merah, Asphalt, Marshall

How to Cite: Evie Dwi, Kamaluddin Lubis, Nuril Mahda.Pengaruh Penggunakan Tanah Merah Sebagai Filler Pada Campuran Aspal AC-BC Terhadap Nilai Marshall. JCEBT (Journal of Civil Engineering, Building and Transportation). 5 (1): $17-25$ 


\section{PENDAHULUAN}

Air yang menggenangi atau masuk ke dalam pori perkerasan jalan merupakan salah satu faktor penyebab rusaknya jalan. Oleh sebab itu, bagian atas jalan diusahakan memiliki sifat kedap air. Sifat kedap air diperoleh dengan menggunakan bahan pengikat dan pengisi pori- pori antar agregat, seperti aspal atau semen Portland (Bethalia Adventi, 2018). Jalan raya terdiri dari beberapa lapisan, salah satunya adalah laston lapis aus. Laston lapis aus ( AC-WC) merupakan lapisan paling atas dari struktur perkerasan yang berhubungan langsung dengan roda kendaraan, mempunyai tekstur yang lebih halus dibandingkan dengan laston lapis pondasi (Asphalt Concrete- Binder Course). Lapisan ini merupakan lapisan perkerasan yang terletak dibawah lapisan aus wearing course dan diatas lapisan pondasi base course. Karakteristik yang terpenting pada campuran ini adalah stabilitas. Untuk memenuhi karakteristik tersebut maka diperlukan campuran aspal yang tepat dan juga bahan pendukung/ pengisi (filler).

Persyaratan filler menurut Kementrian Pekerjaan Umum Direktorat Jendral Bina Marga tahun 2010 revisi 1 harus dalam kondisi kering, bebas dari gumpalan- gumpalan dan lolos ayakan 200. Pada penelitian ini kadar bahan pengisi dibatasi antara 2\% hingga $8 \%$ dari berat total campuran aspal beton dan bahan pengisi (filler) yang digunakan adalah abu tanah merah.

Maksud penelitian adalah mengetahui pengaruh penggunaan filler abu Tanah Merah dalam campuran Aspal AC-BC terhadap karakteristik Marshall.

Tujuan dari penelitian ini adalah Untuk menemukan alternatif baru dari bahan filler aspal dan untuk mengetahui nilai parameter Marshall aspal akibat penggunaan filler abu tanah merah dengan variasi campuran $2 \%$ dan $4 \%$ pada kadar aspal 4,5\%; 5\%;5,5\%; 6\%; dan 6,5\%. Dan adapun masalah yang harus dibahas adalah pakah penggunaan filler Tanah Merah berpengaruh terhadap karakteristik Marshall dan dapat digunakan sebagai bahan campuran pada perkerasan jalan? Dan bagaimana pengaruh serta perbandingan nilai Marshall antara filler tanah merah $2 \%$ dan $4 \%$ pada kadar aspal 4,5\%; 5\%;5,5\%; 6\%; dan 6,5\%.

Pengumpulan data dilakukan melalui pemeriksaan terhadap sifat- sifat fisik agregat kasar, agregat halus, filler (tanah merah) dan pengujian aspal. Pengujian ini meliputi pengujian gradasi saringan, berat jenis, dan penyerapan agregat kelekatan agregat terhadap aspal dan keausan agregat dengan menggunakan mesin abrasi los angeles. Pengujian aspal 
meliputi pengujian berat jenis, penetrasi. Pengujian tersebut merujuk pada beberapa SNI dan Modul buku yang digunakan sebagai refrensi.

\section{Metode Perencanaan Campuran}

Perencanaan campuran pada campuran beraspal terdiri dari perencanaan komposisi agregat, kadar aspal optimum, variasi kadar campuran aspal, serta variasi kadar tanah merah sebagai pengganti filler. Agregat yang digunakan merupakan agregat yang sudah diui dan memenuhi spesifikasi yang telah disesuaikan. Beberapa tahap yang dilakukan dalam penelitian ini adalah seperti persiapan dan pengujian bahan, mix design atau job mix formula, pembuatan benda uji dan pengujian aspal.

\section{Metode Marshall test}

Pengujian dengan metode dan alat Marshall pertama kali diperkenalkan oleh Bruce Marshall, Mississipi State Highway Departement pada tahun 1948 dan selanjutnya dikembangkan oleh U.S Corps of Engineer. Alat Marshall merupakan alat tekan yang dilengkapi dengan proving ring (cincin penguji) berkapasitas 22,2 kN (5000 lbf) dan flowmeter. Proving ring digunakan untuk mengukur nilai stabilitas dan flowmeter untuk mengukur kelelehan plastis atau flow. Benda uji Marshall berbentuk silinder berdiameter 4 inchi $(10,16 \mathrm{~cm})$ dan tinggi 2,5 inchi $(6,35 \mathrm{~cm})$.
Dengan pemeriksaan menggunakan alat Marshall diperoleh data-data stabilitas, kelelahan plastis (flow), persen rongga dalam agregat, berat volume. Untuk memastikan suatu campuran aspal panas sudah memenuhi persyaratan-persyaratan yang sudah ditetapkan oleh Direktorat Jendral Bina Marga atau Departemen Pekerjaan Umum, maka perlu dilakukan test dengan alat Marshall.

\section{HASIL DAN PEMBAHASAN}

\section{Pengujian Agregat}

Pada tahap ini peneliti melakukan pemeriksaan pada agregat baik itu agregat kasar (coarse aggregate) dan agregat halus (fine aggregate), tahapan penelitian ini untuk mendapatkan hasil gradasi agregat yang sesuai dengan Spesifikasi Umum Bina Marga 2010 Divisi 6 Revisi III, maka kombinasi agregat untuk masing- masing campuran ditentukan berdasarkan fraksifraksi agregat yang penggabungannya menggunakan cara analitis. Data dalam penelitian ini adalah data yang langsung diperoleh dari pengujian laboratorium yang meliputi proses pengolahan data.

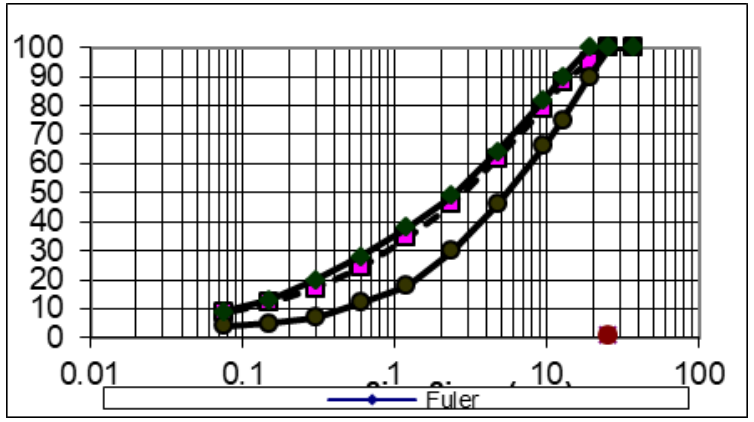

Gambar 1. Kurva Gradasi Agregat Campuran 
Evie Dwi, Kamaluddin Lubis, Nuril Mahda.(2021).Pengaruh Penggunakan Tanah Merah Sebagai Filler Pada Campuran Aspal AC-BC Terhadap Nilai Marshall

Pemeriksaan Berat Jenis Campuran Agregat Kasar

Pemeriksaan ini dimaksudkan untuk menentukan berat jenis (bulk specific gravity), berat jenis kering permukaan jenuh (saturated Surface Dry $=$ SSD), berat jenis semu (Apparent Spesific gravity), dan penyerapan agregat dari agregat kasar.

Tabel 1. Hasil Pengujian Agregat Kasar

\begin{tabular}{lc}
\hline Jenis Pemeriksaan & Percobaan \\
Berat benda uji kering oven (BK) & 5000 gram \\
Berat benda uji kering permukaan jenuh (BJ) & 5053,4 gram \\
Berat benda uji dalam air (BA) & 3151,7 gram \\
Berat jenis (bulk) & \\
BK/ BJ-BA & 2,63 \\
BJ kering permukaan jenuh BJ/BJ-BA & 2,67 \\
BJ semu (apparent) & \\
BK/BK-BA & 2,705 \\
Penyerapan (absorption) & \\
BJ-BK/BK X100 & $1,068 \%$ \\
\hline
\end{tabular}

\section{Agregat Halus}

Tabel 2. Persiapan dan Hasil Berat Jenis Agregat Halus

\begin{tabular}{lc}
\hline \multicolumn{1}{c}{ Jenis Pemeriksaan } & Percobaan \\
Berat benda uji kering permukaan jenuh & 500 gram \\
(SSD) & \\
Berat benda uji kering oven (BK) & 437 gram \\
Berat piknometer dan air pada suhu $25^{\circ} \mathrm{C}$ & 507 gram \\
(B) &
\end{tabular}

Berat piknometer + benda uji (SSD) + air 816 gram (BT)

$\begin{array}{lr}\text { Berat jenis (Bulk) } & 2,28 \\ \text { Berat kering permukaan jenuh } & 2,62 \\ \text { BJ semu (apparent) } & 3,41 \\ \text { Penyerapan (absorption) } & 14.42\end{array}$

Dari percobaan diperoleh nilai berat jenis agregat kasar 2,63 dengan penyerapan 1,068\%. Sedangkan untuk agregat halus didapatkan nilai berat jenis sebesar 2,28 dengan penyerapan $14,42 \%$.

\section{Pemeriksaan Filler}

Bahan pengisi harus bebas dijaga kebersihannya dari semua bahan yang tidak dikehendaki atau campur aduk dari bahan lain. Bahan pengisi agregat halus harus kering dan lolos saringan No. 200. Filler diyakini dapat memperbaiki adhesi antara agregat dan aspal. Standar pengujian yang digunakan adalah AASHTO T- 85-81 dan SNI M-0201994-03 spesifikasi tertahan $70 \%$.

\section{Pemeriksaan Aspal}

Hasil dari pengujian yang dilakukan didapatkan berat jenis aspal sebesar 1.027. dan untuk hasil penetrasi dari aspal dapat dilihat pada tabel berikut:

Tabel 3. Pemeriksaan penetrasi

\begin{tabular}{lc}
\hline \multicolumn{2}{c}{ Pemeriksaan penetrasi aspal } \\
Pemeriksaan sampel 1 & 101.2 \\
Pemeriksaan sampel 2 & 101 \\
Pemeriksaan sampel 3 & 99.4 \\
Rata-rata & 100.53 \\
\hline
\end{tabular}

\section{Hasil Perencanaan Campuran}

Perencanaan campuran (Job Mix Formula) dimaksudkan untuk menentukan proporsi campuran baik agregat kasar, agregat halus dan filler yang sesuai dengan persyaratan/spesifikasi gradasi. Pada penelitian ini digunakan tanah merah sebagai bahan pengganti filler pada aspal 
untuk mengetahui apakah tanah merah yang dicampur dengan aspal dapat digunakan persyaratan mutu campuran yang diperlukan dapat dilihat pada tabel dibawah ini:

Table 4. Persyaratan Mutu Campuran

Kadar aspal terhadap 5-7

berat campuran (\%)

Density $(\mathrm{gr} / \mathrm{ml}) \quad$ Min 2.228

Stability $(\mathrm{kg}) \quad$ Min 800

Flow (mm) 2-4

$\% \quad$ Rongga terhadap 3-5

campuran (VIM)

\% Rongga dalam agregat Min 15

(VMA)

\% Rongga terisi aspal Min 65

(VFA)

Sumber: Spesifikasi Umum Bina Marga 2010 Divisi 6 Revisi III

Pada penelitian ini cetakan (mould) yang digunakan memiliki spesifikasi sebagai berikut:

-Diameter : 10,1cm -Tinggi:7,5cm-Total Campuran : 1200gr -Kadar aspal : 4,5\%. $5 \% .5,5 \% .6 \% .6,5 \%$

\section{Filler Tanah Merah 2\%}

a. Kadar Aspal 4,5\% = 54gr (berat total campuran agregat $=1200$ gr, kadar aspal 4,5\% maka untuk mendapatkan berat aspalnya : $1200 \times 4,5 \%=54 \mathrm{gr}$ ).

$$
\begin{aligned}
& \mathrm{CA}=15 \% \times 1146=171,9 \mathrm{gr} \\
& \mathrm{MA}=40 \% \times 1146=458,4 \mathrm{gr} \\
& \mathrm{FA}=35 \% \times 1146=401,1 \mathrm{gr} \\
& \text { Sand }=8 \% \times 1146=91,68 \mathrm{gr} \\
& \text { Filler }=2 \% \times 1146=\frac{22,92 \mathrm{gr}}{\mathbf{1 1 4 6} \mathbf{~ g r}}
\end{aligned}
$$

b. Kadar Aspal 5\% = 60 gr

$$
\mathrm{CA}=15 \% \times 1140=171 \mathrm{gr}
$$

$$
\begin{aligned}
& \mathrm{MA}=40 \% \times 1140=456 \mathrm{gr} \\
& \mathrm{FA}=35 \% \times 1140=399 \mathrm{gr} \\
& \text { Sand }=8 \% \times 1140=91,2 \mathrm{gr} \\
& \text { Filler }=2 \% \times 1140=\frac{22,8 \mathrm{gr}}{\mathbf{1 1 4 0} \mathbf{~ g r}}
\end{aligned}
$$

c. Kadar Aspal 5,5\% $=66 \mathrm{gr}$

$\mathrm{CA}=15 \% \times 1134=170,1 \mathrm{gr}$

$\mathrm{MA}=40 \% \times 1134=453,6 \mathrm{gr}$

$\mathrm{FA}=35 \% \times 1134=396,9 \mathrm{gr}$

Sand $=8 \% \times 1134=90,72 \mathrm{gr}$

Filler $=2 \% \times 1134=22,68 \mathrm{gr}$

$$
1134 \mathrm{gr}
$$

d. Kadar Aspal 6\% $=72 \mathrm{gr}$

$$
\begin{aligned}
& \mathrm{CA}=15 \% \times 1128=169,2 \mathrm{gr} \\
& \mathrm{MA}=40 \% \times 1128=451,2 \mathrm{gr} \\
& \mathrm{FA}=35 \% \times 1128=394,8 \mathrm{gr} \\
& \text { Sand }=8 \% \times 1128=90,24 \mathrm{gr} \\
& \text { Filler }=2 \% \times 1128=\frac{22,56 \mathrm{gr}}{\mathbf{1 1 2 8} \mathbf{~ g r}}
\end{aligned}
$$

e. Kadar Aspal 6,5\% = $78 \mathrm{gr}$

$$
\begin{aligned}
& \mathrm{CA}=15 \% \times 1122=168,3 \mathrm{gr} \\
& \mathrm{MA}=40 \% \times 1122=448,8 \mathrm{gr} \\
& \mathrm{FA}=35 \% \times 1122=392,7 \mathrm{gr} \\
& \text { Sand }=8 \% \times 1122=89,76 \mathrm{gr} \\
& \text { Filler }=2 \% \times 1122=\frac{22,44 \mathrm{gr}}{\mathbf{1 1 2 2} \mathbf{~ g r}}
\end{aligned}
$$

Setelah mendapatkan hasil perencanaan campuran maka selanjutnya dilakukan pencetakan benda uji. Pengujian ini dilakukan menggunakan alat Marshall dengan 5 variasi kadar aspal tersebut. Dengan 3 buah benda uji untuk setiap masing- masing kadar aspal.

\section{Filler Tanah Merah 4\%}

a. Kadar Aspal 4,5\% = 54gr (berat total campuran agregat $=1200$ gr, kadar aspal 4,5\% maka untuk mendapatkan berat aspalnya : $1200 \times 4,5 \%=54 \mathrm{gr}$ ).

$$
\begin{aligned}
& \mathrm{CA}=15 \% \times 1146=171,9 \mathrm{gr} \\
& \mathrm{MA}=33 \% \times 1146=378,18 \mathrm{gr} \\
& \mathrm{FA}=36 \% \times 1146=412,56 \mathrm{gr} \\
& \text { Sand }=12 \% \times 1146=137,52 \mathrm{gr} \\
& \text { Filler }=4 \% \times 1146=45,84 \mathrm{gr}
\end{aligned}
$$


Evie Dwi, Kamaluddin Lubis, Nuril Mahda.(2021).Pengaruh Penggunakan Tanah Merah Sebagai Filler Pada Campuran Aspal AC-BC Terhadap Nilai Marshall

b. Kadar Aspal 5\% = $60 \mathrm{gr}$

$\mathrm{CA}=15 \% \times 1140=171,9 \mathrm{gr}$

$\mathrm{MA}=33 \% \times 1140=376,2 \mathrm{gr}$

$\mathrm{FA}=36 \% \times 1140=410,4 \mathrm{gr}$

Sand $=12 \% \times 1140=136,8 \mathrm{gr}$

Filler $=4 \% \times 1140=45,6 \mathrm{gr}$

$1140 \mathrm{gr}$

c. Kadar Aspal 5,5\% $=66$ gr

$\mathrm{CA}=15 \% \times 1134=170,1 \mathrm{gr}$

$\mathrm{MA}=33 \% \times 1134=374,22 \mathrm{gr}$

$\mathrm{FA}=36 \% \times 1134=408,24 \mathrm{gr}$

Sand $=12 \% \times 1134=136,08 \mathrm{gr}$

Filler $=4 \% \times 1134=45,36 \mathrm{gr}$

$1134 \mathrm{gr}$

d. Kadar Aspal 6\% = 72 gr

$\mathrm{CA}=15 \% \times 1128=169,2 \mathrm{gr}$

$\mathrm{MA}=33 \% \times 1128=372,24 \mathrm{gr}$

$\mathrm{FA}=36 \% \times 1128=406,08 \mathrm{gr}$

Sand $=12 \% \times 1128=135,36$ gr

Filler $=4 \% \times 1128=45,12 \mathrm{gr}$

\section{$1128 \mathrm{gr}$}

e. Kadar Aspal 6,5\% $=78 \mathrm{gr}$

$\mathrm{CA}=15 \% \times 1122=168,3 \mathrm{gr}$

$\mathrm{MA}=33 \% \times 1122=370,26 \mathrm{gr}$

$\mathrm{FA}=36 \% \times 1122=403,92 \mathrm{gr}$

Sand $=12 \% \times 1122=134,64 \mathrm{gr}$

Filler $=4 \% \times 1122=44,88 \mathrm{gr}$

1122 gr

Setelah mendapatkan hasil perencanaan

campuran maka selanjutnya dilakukan

pencetakan benda uji. Pengujian ini

dilakukan menggunakan alat Marshall

dengan 5 variasi kadar aspal tersebut.

Dengan 3 buah benda uji untuk setiap

masing- masing kadar aspal.

\section{Hasil Parameter Marshall}

\section{Nilai Stabilitas}

Tabel 5. Stabilitas Filler Tanah Merah 2\%

$\begin{array}{ll}4,50 & 1003,84 \\ 5,00 & 1237,56 \\ 5,50 & 1398,76 \\ 6,00 & 1288,31 \\ 6,50 & 1093,19\end{array}$

Tabel 6. Stabilitas filler Tanah Merah 4\%

$\begin{array}{cc}\% \text { Bit By } & \text { Stability } \\ 4,50 & 1017,35 \\ 5,00 & 1201,16 \\ 5,50 & 1275,21 \\ 6,00 & 1297,13 \\ 6,50 & 1123,11\end{array}$

Stabilitas yang diperoleh dari kedua variasi Filler dapat dilihat pada kedua table diatas menunjukkan bahwa nilai memenuhi standar spesifikasi yang dikeluarkan Bina Marga yaitu sebesar 800 kg. Nilai stabilitas tertinggi yaitu menggunakan $2 \%$ filler tanah merah dengan nilai sebesar $1325 \mathrm{~kg}$ sedangkan dengan menggunakan filler $4 \%$ mendapatkan nilai sebesar $1265 \mathrm{~kg}$.

\section{Nilai Kelelehan (Flow)}

Tabel 7. Kelelehan filler Tanah Merah 2\%

$\begin{array}{cc}\text { \% Bit By } & \text { Flow } \\ 4,50 & 2,533 \\ 5,00 & 3,367 \\ 5,50 & 3,500 \\ 6,00 & 4,600 \\ 6,50 & 5,200\end{array}$

Tabel 8. Kelelehan filler Tanah Merah 4\%

$\begin{array}{cc}\% \text { Bit By } & \text { Flow } \\ 4,50 & 2,533 \\ 5,00 & 3,367 \\ 5,50 & 3,500 \\ 6,00 & 4,600 \\ 6,50 & 5,200\end{array}$

Dari hasil pengujian pada edua table diatas nilai flow/ pelelehan sudah memenuhi spesifikasi yang distandarkan oleh bina marga yaitu minimal 2 dan maksimum 4 . Nilai kelelehan terbesar terjadi pada 
variasi filler $4 \%$ dengan nilai sebesar $3,55 \mathrm{~mm}$. Penggunaan tanah merah sebagai filler pda campuran variasi $2 \%$ dan $4 \%$ mengalami kenaikan mulai dari awal hingga ahir.

\section{Kepadatan (Density)}

Tabel 9. Density filler T.Merah 2\%

\begin{tabular}{cc}
\hline$\%$ Bit By & BULK DENSITY \\
4,50 & 2,273 \\
5,00 & 2,296 \\
5,50 & 2,302 \\
6,00 & 2,313 \\
6,50 & 2,311 \\
\hline
\end{tabular}

Tabel 10. Density filler Tanah Merah $4 \%$

\begin{tabular}{cc}
\hline$\%$ Bit By & BULK DEN \\
4,50 & 2,276 \\
5,00 & 2,289 \\
5,50 & 2,300 \\
6,00 & 2,310 \\
6,50 & 2,304 \\
\hline
\end{tabular}

Nilai Rongga Udara Dalam Campuran/ VIM (Void In Mixtured)

Tabel 11. VIM filler Tanah Merah 2\%

\begin{tabular}{cc}
\hline \% Bit By & AIR VOID \\
4,50 & 6,715 \\
5,00 & 5,087 \\
5,50 & 4,175 \\
6,00 & 3,029 \\
6,50 & 2,437 \\
\hline
\end{tabular}

Tabel 12. VIM filler Tanah Merah 4\%

\begin{tabular}{cc}
\hline$\%$ Bit By & AIR VOID \\
4,50 & 6,636
\end{tabular}

\begin{tabular}{rl}
5,00 & 5,436 \\
5,50 & 4,279 \\
6,00 & 3,182 \\
6,50 & 2,755 \\
\hline
\end{tabular}

\section{Nilai VMA (Void in the mineral agg.)}

Tabel 13. VMA filler Tanah Merah $2 \%$

\begin{tabular}{cc}
\hline$\%$ Bit By & V M A \\
4,50 & 15,074 \\
5,00 & 14,663 \\
5,50 & 14,910 \\
6,00 & 14,956 \\
6,50 & 15,493 \\
\hline
\end{tabular}

Tabel 14. VMA filler Tanah Merah 4\%

\begin{tabular}{cc}
\hline$\%$ Bit By & V M A \\
4,50 & 14,997 \\
5,00 & 14,973 \\
5,50 & 14,999 \\
6,00 & 15,088 \\
6,50 & 15,767 \\
\hline
\end{tabular}

Nilai VMA atau rongga dalam agregat pada kedua variasi Filler mengalami kenaikan nilai yang hampir sama, kenaikan disebabkan oleh penambahan kadar aspal. Nilai VFA (Void Filled Asphalt)

Tabel 15. VFA filler Tanah Merah 2\%

\begin{tabular}{cc}
\hline \% Bit By & V M A \\
4,50 & 15,074 \\
5,00 & 14,663 \\
5,50 & 14,910 \\
6,00 & 14,956 \\
6,50 & 15,493 \\
\hline \multicolumn{2}{c}{ Tabel 16. VFA filler Tanah Merah 4\% } \\
\hline \% Bit By & V M A \\
4,50 & 14,997 \\
5,00 & 14,973 \\
5,50 & 14,999 \\
6,00 & 15,088 \\
6,50 & 15,767 \\
\hline
\end{tabular}


Nilai VFA dapat dilihat dari kedua grafik bahwa volume pori rongga cenderung naik ddan mendapatkan nilai rata- rata sebbesar $68 \%$ dan diketahui memenuhi syarat yang ditetapkan yaitu $65 \%$.

\section{Nilai Marshall Quotient (MQ)}

Tabel 17. MQ filler Tanah Merah 2\%

\begin{tabular}{cc}
\hline$\%$ Bit By & MQ \\
4,50 & 396,252 \\
5,00 & 367,593 \\
5,50 & 399,645 \\
6,00 & 280,067 \\
6,50 & 210,229 \\
\hline
\end{tabular}

Tabel 18. MQ filler Tanah Merah 4\%

\begin{tabular}{cc}
\hline$\%$ BIT BY & MQ \\
4,50 & 401,586 \\
5,00 & 356,780 \\
5,50 & 364,345 \\
6,00 & 281,985 \\
6,50 & 215,983 \\
\hline
\end{tabular}

Dari hasil penelitian pada table 17 dan 18 diatas nilai marshall quotient (MQ) tertinggi terjadi pada filler dengan variasi $2 \%$ yaitu sebesar $385 \mathrm{~kg} / \mathrm{mm}$. Nilai MQ yang didapat menunjukkan bahwa telah memenuhi spesifikasi bina marga

\section{Kesimpulan}

Berdasarkan penelitian yang telah dilakukan maka dapat disimpulkan bahwa nilai hasil uji Marshall perbandingan antara $2 \%$ tanah merah dengan $4 \%$ tanah merah menghasilkan hasil yang bagus, baik nilai stabilitas flow, maupun hasil marshal quotient. Hasil pengujian Marshall dengan variasi campuran 2\% Filler Tanah Merah didapatkan kadar aspal optimum sebesar 5,2\% dan memiliki nilai stabilitas rata- rata sebesar $1325 \mathrm{~kg}$. Sedangkan untuk variasi campuran $4 \%$ filler Tanah Merah didapatkan hasil kadar optimum sebesar 5,3\% dan memiliki nilai stabilitas rata- rata sebesar $1365 \mathrm{Kg}$. Berdasarkan hasil data tersebut diketahui bahwa semakin banyak menggunakan kadar filler maka semakin berpengaruh terhadap campuran aspal. Nilai Stabilitas yang didapatkan mencapai spesifikasi yang sudah ditetapkan yaitu Spesifikasi Bina Marga 2010 Divisi 6 Revisi III dengan nilai stabilitas minimal $800 \mathrm{~kg}$. Penggunaan abu Tanah Merah yang lolos saringan 200 sebagai filler pengganti abu batu pada campuran aspal beton AC-BC yang menggunakan jenis aspal penetrasi 60/70 dapat memenuhi syarat spesifikasi Umum Bina Marga 2010.

\section{DAFTAR PUSTAKA}

Abdillah, M. Zainuddin. 2018. Subtitusi Filler Pada CAmpuran Aspal Dengan Fly Ash Dan Serbuk Batu Bata. Fakultas Teknik Universitas Islam Lamongan

Auditia, A Bethalia. 2018. Pengaruh Penggunaan Bubuk Gypsum Sebagai Filler Dalam Campuran Aspal. Fakultas Teknik dan Ilmu Komputer. Universitas Kristen Krida Wacana Bina Marga, Spesifikasi Umum 2010( revisi 3) Divisi 6 Perkerasan Aspal.

Esentia,Advanty. 2014. Pengaruh Penggantian Sebagian Filler Semen Dengan Kombinasi 40\% Serbuk Batu Bata Dan 60\% Abu Cangkang Lokan Pada Campuran Asphalt Concrete 
Binder Course (AC-BC). Fakultas Teknik Universitas Bengkulu.

Hardiyatmo, H. Christady. 2015. Pemeliharaan Jalan

Raya. Gajah Mada University Press.

Yogyakarta.

Wesli,Zulfhazli. 2016. Penggunaan Abu Batu Bara Sebagai Filler Pada Campuran Aspal Beton $A C-B C$. Jurusan Teknik Sipil Universitas Malikulssaleh. 